\title{
THE DIFFERENCES IN VIEW BETWEEN MANAGERS AND EMPLOYEES OF ENTERPRISES OF LATVIA IN REGARD TO THE PROVISION OF MENTAL WELL-BEING IN THE WORKING ENVIRONMENT
}

\author{
Dace Bole ${ }^{1}$, Master in management science
}

\begin{abstract}
The need for mental well-being is substantiated in the working environment by the EU legislation and research. Research is carried out on the opportunities of creating comprehensive well-being at the workplace to promote the productivity of sustainable personnel. The mental well-being of personnel is studied in contexts such as: ecologies of working environment (including occupational safety, occupational health) and quality of life; adaptation and integration of employees into the workplace; psychosocial risks; organizing and conducting of an inclusive mental well-being. These contexts also can be defined as groups of psychosocial factors influencing mental well-being. The goal of the study was to find out how managers and employees of the companies and institutions of Latvia explain mental well-being and its provision in the working environment in order to identify problems and solutions to problems of mental well-being in the working environment. A quantitative approach was used in the research -in cooperation with the SKDS research centre there was worked and carried out online questionnaire (CAWI) in written and extramarital forms for managers of companies / enterprise $(\mathrm{N}=263)$ and employees $(N=570)$ of Latvia. The substantiation of the survey was to get approval for the conclusions, which had been obtained using the literature analysis. The indicators of difference in the results were obtained using a Kolmogorov-Smirnov test for two groups (Two-Sample Kolmogorov-Smirnov Test). The results show that both managers and employees have got a good understanding of the usefulness of mental well-being in management of a company/enterprise and its personnel. There were found statistically significant differences in the evaluation of managers and personnel for the aspects of mental well-being: the awareness of the concept of "mental wellbeing of personnel"; the assessment of the mental well-being of personnel: the assessment of psychosocial risk factors, frequency of the assessment of work-related risks; the assessment of the promotion of mental well-being of personnel: the assessment of the practice of promoting mental well-being, the formal formulation of mental well-being, the opportunity for employees to participate in mental well-being promotion activities, the assessment of the importance of the mental well-being of personnel to sustainable development of the company/enterprise. It has been concluded that the mental well-being of personnel is a continuous process of the type of cycles where the individual sense of mental well-being of each employee and the functional action of synergy creates mental well-being in the company as a system. According to the conceptualized promotion of the mental well-being of the personnel in the practice of companies /enterprises of Latvia, such management approach is implemented partially. At the same time, managers and employees appreciate the importance of such management. Overall, the results show the necessity for managers to communicate with employees on mental well-being issues. The study identifies the most important criteria for the assessing the mental well-being of personnel and the topical areas of concern for the mental well-being of personnel.
\end{abstract}

Key words: the assessment of mental well-being of personnel in organizations of Latvia; promotion of mental well-being in the organization, criteria of mental well-being in the organization.

JEL code: I15 - Health and Economic Development

\section{Introduction}

The necessity for mental well-being in the work environment is justified by the legislation of EU, researches (European Pact for Mental..., 2008; Joint Declaration on Mental..., 2014). The issue of comprehensive prosperity is topical (Gallagher M.W., et al., 2009) to promote sustainable personnel productivity. Modern research shows that the issues of mentality and mental well-being are topical in the enterprises (Bowman T.J., 2004; Marques J., Dhiman S., 2014).

Therefore, there is raised the question of the study: what are the differences in the views of the managers of organizations (companies and enterprises) of Latvia and their employees about the mental well-being of the personnel, the provision of mental well-being in the working environment?

\footnotetext{
${ }^{1}$ Contacts to be added to the author, as a footnote at the bottom of the first page ( 6 point Verdana font)
} 
The goal of the study was to find out how managers and employees of the companies and enterprises of Latvia explain mental well-being and its provision in the working environment in order to identify the problems and their solutions of mental well-being in the working environment.

The tasks of the study were: to collect and analyse the literature on mental well-being in the working environment and to improve its provision; to conduct a questionnaire in order to research the topicalities, problems and provision of mental well-being in the companies and enterprises of Latvia; to compile and analyse the results identifying the necessity and opportunities for improvement of mental well-being provision.

In the study, written and online questionnaire (CAWI) have been used for managers and employees of the companies/enterprises by the research centre SKDS. The survey was conducted in March and April in 2016 and there were used two types of questionnaires: a questionnaire for employees and a questionnaire for managers. The total amount of respondents there were 263 managers and 570 employees. The difference indicators of the results were obtained using a Kolmogorov-Smirnov test for two groups (Two-Sample Kolmogorov-Smirnov Test).

The novelty and topicality of the study is related to the fact that the mental well-being of the personnel as the concept of the most comprehensive welfare in Latvia has been researched little, and the author of the study according to the number of respondents shows sufficient understanding of the usefulness of mental well-being of managers and employees in the management of the personnel of the companies/enterprises of Latvia at the trend level.

However, at the same time there were also statistically significant differences in the evolutions of managers and employees for the aspects of mental well-being of the personnel that could be identified as a challenge to comprehensive mental well-being at work.

\section{Research results and discussion}

\section{The concept of personnel mental well-being}

Well-being concept, was created by Seligman after more than 20 years, is studied in relation to socio-demographic factors (gender, age, education, marriage and relationships, income, etc.), personality factors (extraversion, introversion, etc.), goals and values, culture etc. (Diener E. et al., 2009; Seligman, 2011). From the point of view of mental well-being, the author considers Seligman's view that well-being is a construct and as well as well-being elements - real things that are directly measured units because well-being is not just the reflection of people about thoughts, feelings or positive emotions. Every welfare element should coincide to the criteria: 1) it contributes to wellbeing; 2) for people, well-being is the help to get something else (Seligman M.E.P., 2011).

The category of mental well-being is significantly related to the mental health category (Duque L., 2009; Vorone S., 2012). Conceptually, the relationship between physical and mental health is important in the working environment (Duque L., 2009; Joint Declaration on Mental..., 2014).

The author, summarizing the views (Diener E., et al., 2009; Seligman M.E.P., 2011; Vorone S., 2012; Mental health: strengthening..., 2014), conceptualizes the concept of "well-being" including types of well-being: economical, physical, psychosocial, mental. It can be concluded that well-being is a multidimensional phenomenon, and mental well-being as a type of well-being that is the result of the integration of all other forms of well-being is also a multidimensional phenomenon.

The author relies on the approach adopted by S. Vorone (Vorone S., 2012) in Latvia - to study well-being in a holistic way using the term "psychosocial well-being" to define the concept of multidimensional well-being which essentially means integrating the subjective, psychological and social aspects of a happy and meaningful life. 
At the same time, the author extends the framework setting the goal - the promotion of the mental well-being of the personnel of the organization which means that the ideal goal of personnel management is employee's prosperity based on the integration of other well-being and wellness aspects (Seligman M.E.P., 2011; Vorone S., 2012; Huppert F.A., So T.T.C., 2009).

The author, based on literature analysis and his / her work experience in personnel management, defines the mental well-being of the personnel as a process and state that includes several components: wellness, a sense of mental well-being, productive activity. Therefore, the mental wellbeing of the personnel is employee's individual well-being (physical and emotional). Well-being determines positive, optimistic self-acceptance, awareness of the situation, the quality of thinking (accuracy, breadth, creativity) - i.e. the mental aspect - the sense of mental well-being. Mental wellbeing involves a physical, emotional (mental), mental health in a unified system, and mental health is the most important factor influencing mental well-being. Mental well-being is a continuous process of transformation of cycles, with temporarily fixed moments of mental well-being and a relatively sTable state of mental well-being - a state of balance and harmony that ensures the continuity of the process. Each employee's individual sense of mental well-being and its appropriate functional behaviour through synergy creates mental well-being in the organization as in the system that promotes its effectiveness.

In the analysis of the literature, especially the published experiences of other countries (the UK, Germany, Canada, etc.) in the research on mental health and mental well-being in the enterprises and various projects to promote mental health and mental well-being (A Manual for Promoting..., 2009, Mental health promotion...,2011, Recommendations for implementing...,2014; Workplace Mental Health..., 2015) the author classified factors of employees' well-being and effect of factors: individual level and level of the company/enterprise. These factors are interacting - i.e. one factor can cause the influence of other factors, which in turn affects the initial factor.

In order to promote mental well-being of personnel, promoting health programs are useful. The promotion of mental health is defined as the process of improving protection factors which improves individual, social and environmental conditions which ensures optimal health and promotes person's full development, improves the quality of his/her life. There are two supported broad categories and programs of mental health which are distinguished: 1) mental illness, disorder prevention or preventive work; 2) promoting of mental health. Prevention and promotion of mental health are not mutually exclusive categories because there is necessary a comprehensive approach including both prevention and health promotion (Mental health promotion ..., 2011).

Promoting mental health at the workplace is one of the priorities of the Community Health and Safety at Work Strategy (Mental Health promotion..., 2011). The best practice analysis of mental health and well-being in Europe (Mental Health Promotion, 2011) and the material prepared by researchers and practitioners of Canada (Workplace Mental Health..., 2015) there are promoted the criteria which characterize the main principles. The key principles for promoting mental health and well-being are defined as: theoretical background, holistic approach, regularity, monitoring, active involvement of employees and management, evaluation, continuity and continuity of the process, effective communication, provision of training and support. It is useful to carry out research on the mental well-being of the personnel in the company/enterprise in the areas such as: work environment ecology (including occupational safety, occupational health) and quality of life; adapting and integrating employees into the workplace; psychosocial risks; features of a mental well-being organization. 


\section{Evaluation results of personnel mental well-being in companies and enterprises of Latvia}

The results of the comparison of the concept "mental well-being of personnel" are summarized in the Table (Table 1).

The relative and differential significance indicators of respondents' awareness of the meaning of 'mental well-being of personnel'

\begin{tabular}{|l|c|c|c|c|c|}
\hline Selection/Indicators & Yes & No & Hard to say & Z criterion & $\begin{array}{c}\text { Significance } \\
(\mathbf{p})\end{array}$ \\
\cline { 1 - 4 } Managers (N=263) & $33.8 \%$ & $52.5 \%$ & $13.7 \%$ & & \multirow{2}{*}{1.83} \\
\cline { 1 - 5 } Employees (N=570) & $20.2 \%$ & $67.4 \%$ & $12.5 \%$ & 0.002 \\
\hline
\end{tabular}

Source: author's calculations based on results of the survey

The results show (Table 2) that managers have encountered this concept more often, and employees are relatively uncommon. Relatively often, respondents in both surveys find it difficult to answer a question that also indicates a lack of awareness and can reduce the use of opportunities for personnel to promote mental well-being.

The results of the assessment of the practice of promoting mental well-being of personnel are summarized in the Table (Table 2).

\section{Frequency of respondents' opinions on the existence of mental well-being practices in the enterprise/institution and indicators of significance of differences in the selection of managers and employees}

\begin{tabular}{|l|c|c|c|c|c|c|}
\hline Selection/Indicators & $\begin{array}{c}\text { Yes, } \\
\text { absolutely }\end{array}$ & $\begin{array}{c}\text { Yes, } \\
\text { partly }\end{array}$ & No & $\begin{array}{c}\text { Hard to } \\
\text { say }\end{array}$ & Z criterion & $\begin{array}{c}\text { Significance } \\
\text { (p) }\end{array}$ \\
\cline { 1 - 5 } Managers (N=263) & $6.5 \%$ & $36.9 \%$ & $28.9 \%$ & $27.8 \%$ & & \multirow{2}{*}{0.006} \\
\hline Employees $(\mathbf{N = 5 7 0 )}$ & $4.7 \%$ & $26.0 \%$ & $37.9 \%$ & $31.4 \%$ & 1.69 & 0.006 \\
\hline
\end{tabular}

Source: author's based on results of the survey

The results show (see Table 3) that the practice of promoting mental well-being in a company / enterprise is problematic: it is implemented partly, it is difficult to identify if it is or is not implemented; managers value the existence of such practices more than employees.

In the assessment of personnel mental well-being: in the assessment of psychosocial risk factors managers assessed the extent to which they agreed with the statements of risk factors by extending their assessment to their subordinate employees; Employees appreciated the extent to which they agreed to the statements by referring to their paid employment. The results (significance and importance of $Z$ criterion) showed statistically significant differences in 5 measurements from 11 measurements. The factor of a psychosocial risk that can negatively affect mental well-being of the personnel is an opportunity for employees in the company /enterprise to participate in the decision-making and / or adoption of important decisions by employees (21.2 \% of employees do not agree completely and $28.5 \%$ rather disagree than agree that there is such possibility in the company / enterprise; 23.2 \% of managers believe that employees rather do not have such opportunity than they have); less, but, however, an important risk factor can also be considered incomplete sense of security of the stability of your workplace and recognition of the necessity for work, family and work-life balance in the company/ enterprise. The results of the assessment of the frequency of work-related risks indicate the problematic provision of mental well-being very significant differences have been identified: in the view of managers the risk assessment is more frequent than that of employees; comparatively (especially in the selection of employees) the assessment "hard to say" is more often. 
The results of the assessment of work-related risks show that the use of occupational safety assessments and controls is much more common in the view of managers, and comparatively, also employees have indicated it as the most common practice that can be explained by compliance with regulatory requirements in companies / enterprises. In the context of promoting the mental wellbeing of personnel the fact that daily conversations with employees are used by $43.0 \%$ of managers in the risk assessment, although almost 2 times less the use of this method has been reported by employees.

The results of the assessment of the formal formulation of mental well-being (the question: are there included any mental health issues in the policies of personnel management of the company / enterprise or other documents?) are very different, however, in both respondents' selections there is seen the tendency that it is difficult to answer the question about formal formulation of mental well-being in the documents of the company /enterprise.

The classification of the frequency of the results showed that in the selection of managers- higher level managers and representatives from culture and entertainment, financial, social care, and in the selection of employees representing social care, transport logistics and municipal enterprises responded affirmatively more often.

In order to clarify information about the process of mental well-being and to develop the guidelines for process improvement, the managers were asked whether criteria have been developed in the company/enterprise to determine that the promotion of mental well-being is being implemented. The results show that the development and use of criteria for assessing mental well-being is problematic. The classification of the frequency of the results showed that the above mentioned criteria were more often developed in the fields of finance, education, public administration.

In order to be able to make recommendations for improving the mental well-being of personnel, the managers were asked to assess whether by the criteria in the Table could lead to the promotion of mental well-being in the company/enterprise. The results are summarized in the Table (Table 3).

Table 3

Relative ( $\%$ ) indicators of the evaluation of the frequency of the evaluation of potential criteria in the enterprise / institution for the promotion of mental well-being in the selection of the managers $(N=263)$

\begin{tabular}{|l|l|c|c|c|c|c|}
\hline \multicolumn{1}{|c|}{ No } & \multicolumn{1}{|c|}{ Criterion } & $\begin{array}{c}\text { Can } \\
\text { com-pletely } \\
\mathbf{( \% )}\end{array}$ & $\begin{array}{c}\text { Rather } \\
\text { can } \\
\mathbf{( \% )}\end{array}$ & $\begin{array}{c}\text { Rather } \\
\text { cannot } \\
\mathbf{( \% )}\end{array}$ & $\begin{array}{c}\text { Cannot } \\
\text { at all } \\
\text { (\%) }\end{array}$ & $\begin{array}{c}\text { Hard } \\
\text { to } \\
\text { say } \\
(\%)\end{array}$ \\
\hline 1. & $\begin{array}{l}\text { Conversation with an employee about well-being } \\
\text { at work }\end{array}$ & 19.8 & 55.5 & 7.2 & 4.2 & 13.3 \\
\hline 2. & Surveys on employee's psychological well-being & 15.2 & 56.7 & 8.7 & 5.3 & 14.1 \\
\hline 3. & $\begin{array}{l}\text { The strategy of the company / enterprise is to } \\
\text { provide a healthy lifestyle at the workplace }\end{array}$ & 14.1 & 54.8 & 12.2 & 4.2 & 14.8 \\
\hline 4. & Managers' observations in daily work & 20.2 & 53.2 & 10.6 & 1.5 & 14.4 \\
\hline 5. & $\begin{array}{l}\text { Satisfaction survey, including mental well-being } \\
\text { issues }\end{array}$ & 16.0 & 49.4 & 11.4 & 6.5 & 16.7 \\
\hline 6. & $\begin{array}{l}\text { Consultation with occupational doctors, } \\
\text { psychologists }\end{array}$ & 13.3 & 43.7 & 15.2 & 7.2 & 20.5 \\
\hline 7. & $\begin{array}{l}\text { Employee's assessment and development } \\
\text { conversations }\end{array}$ & 15.6 & 55.1 & 11.0 & 3.8 & 14.4 \\
\hline
\end{tabular}

Source: author's calculations based on results of the survey

The results show (Table 4) that, when comparing all rating options, the managers consider that interviews with employees about well-being at work and managers' observations in their daily work as the most complete/relevant criteria; more relevant: employee's assessment and development 
conversations; the strategy of the company/enterprise is to provide a healthy lifestyle at the workplace; employees' surveys that include issues of mental well-being assessment. The topicality of the criteria development as well as the necessity for professional development of managers in the issues of mental well-being assessment substantiates often chosen rating "hard to say".

In order to clarify whether and how the promotion of mental well-being happens in the company/enterprise and to get information about that if some of the previously assessed criteria (see Table 4) are being implemented in practice, employees were asked to evaluate: 1) how much do employees agree with the claims of their wages? (claims were reformulated criteria; 2) or, do the employees of the company / enterprise have the opportunity to participate in the assessment of employees' mental well-being? The results showed that partially evaluated potential criteria are being implemented in practice. Problem areas are managers' conversations with their employees about wellness at work once a half year or more, and the surveys of employees' psychological well-being (more often chosen rating "do not agree").Employees' participation in the evaluation of mental wellbeing issues is problematic because $70.7 \%$ of respondents indicated that there was No such participation, but $22.6 \%$ said "hard to say". The results of the assessment of the employees' ability to participate in mental well-being activities show very significant differences: the managers evaluate the ability of employees to participate in such activities higher than the employees themselves. More frequent participation in different physical exercise classes is shown in both selections; less often - in seminars on mental health and mental well-being.

The results of personnel assessment of the importance of mental well-being for sustainable development of an enterprise/company show that overall the mental well-being of personnel is assessed as a very important and important factor for ensuring sustainable development of the company/enterprise, however, a high score ( 7 and 6 out of max 7 possible) has been chosen more frequently in the selection of the managers. The lack of understanding of this issue is evidenced by the relatively often chosen 'hard to say' rating. The explanation of the practical application of the research results is based on the results of the managers' survey which show that there is a sufficient amount of financial, time and personnel resources to ensure the promotion of the mental well-being of the personnel. However, the problem of potential resource assessment is revealed by the relatively often chosen 'hard to say' rating.

\section{Conclusions, proposals, recommendations}

1) The results of the research show the topicality of the personnel for the promotion of mental wellbeing in the companies and enterprises of Latvia, as well as the partial use of such an approach and the partial readiness of the managers and employees to implement such management approach. Understanding of the concept of "mental well-being of personnel" is topical.

2) From a strategic point of view, the problem is the developed criteria by which it can be determined in the company/enterprise that the promotion of the mental well-being of the personnel is implemented as well as the difficulty of assessing potential criteria for assessing such management. The necessity of criteria is in accordance with the conclusion of the literature analysis that well-being is a directly measurable unit, not just a reflection of people. The results of the survey showed the usefulness of the following criteria: conversation with employees about well-being at work and observations of managers in daily work; staff mental well-being issues included in employee evaluation and development negotiations; moving the strategy of the company/enterprise towards providing a healthy lifestyle in the workplace; employee surveys that include issues of mental wellbeing assessment. 
3) In the assessment of the importance of personnel for the promotion of mental well-being in the sustainable development of an enterprise/company, the most common tendency is that it is very important and important for both managers and employees to understand the usefulness of mental well-being in the management of the company/enterprise and their personnel. Conceptually, it means that it is important to clarify the importance of such security in the view of the personnel when planning the provision of mental well-being of the personnel.

4) Survey results showed managers and employees' perceptions of mental well-being, differences in mental well-being at work. There was more frequent awareness of higher level managers ( $1 \%$ probability of error) of the notion of "mental well-being of personnel"; significant differences were observed in the assessment of mental well-being of personnel in the working environment (probability of dominance error $0.01 \%$ and $1 \%$, in some measurements $5 \%$ ): the managers assess psychosocial risk factors as less risky; the managers evaluate the ability of employees to participate in mental well-being activities more than employees themselves; the managers more often than employees believe that at least in part in companies/enterprises there is a practice of promoting mental well-being of personnel; the managers more often than employees consider the importance of mental well-being of the personnel to the sustainable development of a company/enterprise as very important. Overall, the results show the necessity that the managers should communicate with employees about mental well-being issues in order to get accurate feedback on the state of mental well-being of the personnel and the usefulness of measures to promote mental well-being.

The results of the study are controversial in several aspects: the tendency has been observed in the assessment of the mental well-being of the personnel - the managers consider the risk factors are less risky and may be related to the physical and mental health of the employees what is found in the literature analysis according to their work and working environment in a direct and indirect way. Direct commitment managers are easier to observe because they manifest themselves in the physical working environment and at the health of their employees, but the impact of the psychosocial working environment is more difficult to identify. Differences in the results can also be explained by the recognition that the level of psychosocial well-being is determined by subjective and objective (environmental) factors which degree of influence is determined by how important it is for the personality. Employees can assess subjectively the risk factors more visible, in turn the managers assess them more objectively, and objective risk factors may be less visible. However, the results highlight the necessity to improve managers' understanding of two categories and programs of mental health support measures: 1) mental illness, disorder prevention or preventive work; 2) promoting mental health; in the assessment of the promotion of the mental well-being of personnel, the managers assess the ability of employees to participate in mental well-being activities more than employees themselves what can be explained by a different understanding of effective participation - providing access to all relevant information allowing sufficient time for consultations and discussions. Perhaps, employees may not take full advantage of their opportunity, but then the question is whether employees consider the activities are useful because the examples of Good Practice show that if employees find the activities useful, they support them and participate in them; in assessment the importance of mental well-being of personnel to the sustainability of a company/enterprise, the managers more often consider the importance of mental well-being of the personnel as very important, which can be explained by greater awareness of the managers on this issue; evaluating the practice of 
promoting mental well-being of the personnel, the managers evaluate the existence of such practices more than employees, expressing more often that it is partially implemented. Therefore, it is likely that the managers are not sufficiently aware of employees' level of tension and take the necessary activities.

The research showed a controversial issue in the implementation of mental well-being of the personnel: hard-to-identify practices for promoting mental well-being in a company/enterprise and formal formulation of the documents of mental well-being in company/enterprise that can be associated with inadequate awareness and understanding of these issues and/or inadequate identification of mental well-being and indicators.

\section{Bibliography}

1. A Manual for Promoting Mental Health and Wellbeing, ProMenPol Project (2009). Retrieved: http://www.mentalhealthpromotion.net/resources/toolit-manuals/manual-for-the-workplace.pdf. Access: 10.02.2015.

2. Bowman, T. J. (2004). Spirituality at Work: An Exploratory Sociological Investigation of the Ford Motor Company. London: London School of Economics and Political Science. p. 340.

3. Diener, E., Wirtz, D., Tov, W., Kim-Prieto, C., Choi, D., Oishi, S., Biswas-Diener, R. (2009). New Measures of Well-being: Flourishing and Positive and Negative Feelings. Social Indicators Research Series; 39, pp. 247-266.

4. Duque, L. (2009). Mental Health of Expatriates in Finnish Enterprises in Brazil. Dissertation. Turku: University of Turku. Retrieved: https://www.tsr.fi/tsarchive/files/TietokantaTutkittu/2006/106388Loppuraportti.pdf Access: 12.12.2015.

5. European pact for mental health and well - being (2008). Retrieved: http://ec.europa.eu/health/ph_determinants/life_style/mental/docs/pact_en.pdf Access: 10.02.2015.

6. Gallagher, M.W., Lopez, S.J., Preacher, K.J. (2009). The Hierarchical Structure of Well-Being. Journal of Personality; 77(4), pp. 1025-1049.

7. Huppert, F.A., So, T. T. C. (2013). Flourishing Across Europe: Application of a New Conceptual Framework for Defining Well-Being. Social Indicators Research; 110(3), pp. 837-861.

8. Joint Declaration on Mental Health in the Workplace (2014). Conference "Driving Mental Health at the Workplace. Learning from Each Other" material. Retrieved: http://ge.tt/35KUFG42 Access: 08.01.2015.

9. Marques, J., Dhiman, S. (2014). Leading Spiritually: Ten Effective Approaches to Workplace and Spirituality. New York: Palgrave Macmillan. p. 183 p.

10. Mental Health Promotion in the Workplace - A Good Practice Report (2011). European Agency for Safety and Health at Work. Retrieved: https://osha.europa.eu/en/publications/reports/mental-health-promotionworkplace_TEWE11004ENN Access: 05.02.2015.

11. Mental health: strengthening our response (2014). Retrieved: http://www.who.int/mediacentre/factsheets/fs220/en/ Access: 06.09.2014.

12. Recommendations for Implementing Psychosocial Risk Assessment (2014). Conference „Driving mental health at the workplace. Learning from each other" material. Retrieved: http://ge.tt/35KUFG42 Access: 08.01 .2015$.

13. Seligman, M.E.P. (2011). Flourish: A Visionary New Understanding of Happiness and Well-being. New York: Free Press. p. 368.

14. Vorone, S. (2012). Musdienu studejoso psihosocialas labklajibas saturs. Promocijas darbs. Daugavpils: DU. Retrieved: http://dnl.biblio.du.Iv/promocijas/DU_2012_santa_vorone_promdarbs.pdf Access: 17.09.2015.

15. Workplace Mental Health Promotion. How-To Guide (2015). Retrieved: http://wmhp.cmhaontario.ca/ Access: 16.02.2015. 